\title{
Preparation, Characterization, and Application of Magnetic Fe-SBA-15 Mesoporous Silica Molecular Sieves
}

\author{
Huayu Huang, ${ }^{1,2}$ Yongsheng Ji, ${ }^{1}$ Zhenfeng Qiao, ${ }^{1}$ Chuande Zhao, ${ }^{1}$ \\ Jianguo He, ${ }^{1}$ and Haixia Zhang ${ }^{1}$ \\ ${ }^{1}$ Department of Chemistry, Lanzhou University, Lanzhou 730000, China \\ ${ }^{2}$ Department of Science, Nanjing Agricultural University, Nanjing 210095, China
}

Correspondence should be addressed to Haixia Zhang, zhanghx@lzu.edu.cn

Received 24 March 2010; Accepted 19 July 2010

Academic Editor: Xiu-Ping Yan

Copyright ( $) 2010$ Huayu Huang et al. This is an open access article distributed under the Creative Commons Attribution License, which permits unrestricted use, distribution, and reproduction in any medium, provided the original work is properly cited.

\begin{abstract}
Magnetic Fe-SBA-15 mesoporous silica molecular sieves were prepared, characterized, and used for magnetic separation. Wet impregnation, drying, and calcination steps led to iron inclusion within the mesopores. Iron oxide was reduced to the metal form with hydrogen, and the magnetic Fe-SBA-15 was obtained. Fourier-transform infrared spectroscopy confirmed the preparation process from the oxide to metal forms. The structure of magnetic materials was confirmed by Mössbauer spectra. Powder $\mathrm{X}$-ray diffraction data indicated that the structure of Fe-SBA-15 retained the host SBA-15 structure. Brunauer-Emmett-Teller analysis revealed a decrease in surface area and pore size, indicating Fe-SBA-15 coating on the inner surfaces. Scanning electron micrographs confirmed the decrease in size for modified SBA-15 particles. From scanning electron micrographs, it was found that the size of the modified SBA-15 particles decreased. Transmission electron micrographs also confirmed that modified SBA-15 retained the structure of the parent SBA-15 silica. Fe-SBA-15 exhibited strong magnetic properties, with a magnetization value of $8.8 \mathrm{emu} \mathrm{g}^{-1}$. The iron content in Fe-SBA-15 was determined by atom adsorption spectroscopy. Fe-SBA-15 was successfully used for the magnetic separation of three aromatic compounds in water. Our results suggest wide applicability of Fe-SBA-15 magnetic materials for the rapid and efficient separation of various compounds.
\end{abstract}

\section{Introduction}

Mesoporous SBA-15 silica molecular sieves of large pore diameter (up to $30 \mathrm{~nm}$ ) and area (up to $1000 \mathrm{~m}^{2} \mathrm{~g}^{-1}$ ) [1] show excellent homogeneity and stability and can be well controlled for adsorption/desorption processes [2]. Mesoporous silica materials, especially mesoporous SBA-15 molecular sieves, have been modified with 3mercaptopropyl, 3-aminopropyl, octyl, or octadecyl groups for the separation and analysis of inorganic ions, organic compounds, and biological molecules [2-5]. However, SBA15 is notoriously difficult to separate from solution. Magnetic separation is a useful tool because of its fast recovery, high efficiency, and low high cost [6]. Inclusion of magnetic components in modified materials allows convenient and economical magnetic separation instead of centrifugation and filtration steps on application of an appropriate magnetic field [7-9]. Because of their potential applications in this approach, the preparation of $\mathrm{Co}, \mathrm{Co} / \mathrm{Fe}, \alpha-\mathrm{Fe}_{2} \mathrm{O}_{3}$, $\gamma$ - $\mathrm{Fe}_{2} \mathrm{O}_{3}$, and $\mathrm{Fe}_{3} \mathrm{O}_{4}$ magnetic SBA-15 materials have been reported [10-15].

We propose a convenient and effective procedure for iron doping of mesoporous SBA-15 silica because of its excellent magnetic properties. The product was prepared by wet impregnation, calcinations, and reduction. First, the pores of SBA-15 were doped with iron ions. Then $\mathrm{Fe}^{3+}$ was transformed to the oxide form by calcination in the air. Finally, ferric oxide in SBA-15 was reduced with $\mathrm{H}_{2}[7,15,16]$. Figure 1 shows a flow diagram for preparation of magnetic SBA-15. Fourier-transform infrared (FT-IR) spectroscopy, powder X-ray diffraction (XRD), Mössbauer spectra (MS), surface area analysis, scanning electron microscopy (SEM), and transmission electron microscopy (TEM) techniques were used to characterize the material. The magnetic behavior was determined using a vibrating sample magnetometer. The iron content in 


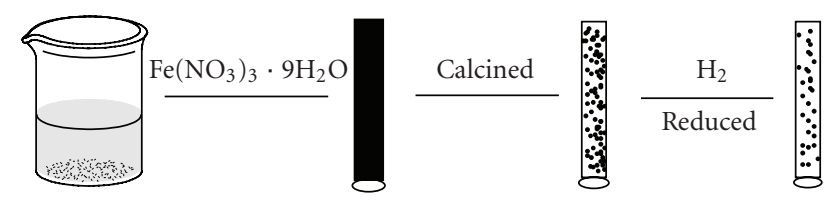

FIGURE 1: Flow diagram for the preparation of magnetic Fe-SBA-15.

Fe-SBA-15 was determined by atom adsorption spectroscopy (AAS).

With the development of petroleum refining and chemical engineering, the release of harmful organic chemicals into the environment has attracted global attention because of their toxicity and widespread use, especially aromatic compounds considered as carcinogenic [7]. The aim of the present study was to develop a method for preparing magnetic SBA- 15 for use as a sorbent to remove benzene and related derivatives from water. The adsorption of benzene, toluene, and ethyl benzene on magnetic SBA-15 particles was determined by gas chromatography (GC).

\section{Materials and Methods}

2.1. Materials. Mesoporous SBA-15 silica molecular sieves were purchased from Changchun Jilin University HighTech. Co. Ltd. (Jilin, China). $\mathrm{Fe}\left(\mathrm{NO}_{3}\right)_{3}$ was purchased from Tianjin Chemical Reagent Co. Ltd. (Tianjin, China). Benzene, toluene, and ethyl benzene were purchased from Sigma (St. Louis, MO, USA). Deionized water was prepared using a Millipore unit (Bedford, MA, USA).

2.2. Sample Preparation. SBA-15 was soaked in $0.1 \mathrm{~mol} \mathrm{~L}^{-1}$ $\mathrm{HCl}$ for $24 \mathrm{~h}$, filtered, washed with deionized water, and dried in an oven at $100^{\circ} \mathrm{C}$ for $8 \mathrm{~h}$.

A sample of $2 \mathrm{~g}$ of SBA- 15 was dispersed in $1 \mathrm{~mol} \mathrm{~L}^{-1}$ $\mathrm{Fe}\left(\mathrm{NO}_{3}\right)_{3}$ solution by ultrasonication for $2 \mathrm{~h}$. The material was filtered under low pressure and dried in an oven at $100^{\circ} \mathrm{C}$. Samples were calcined in a muffle furnace at $750^{\circ} \mathrm{C}$ for $6 \mathrm{~h}$ to obtain a red powder, which was then reduced under a $\mathrm{H}_{2}$ flow $\left(35 \mathrm{~mL} \mathrm{~min}^{-1}\right)$ at $800^{\circ} \mathrm{C}$ for $6 \mathrm{~h}$. The final product was designated Fe-SBA-15.

2.3. Characterization. FT-IR spectra of SBA-15 particles were recorded before and after modification on a Nicolet (USA) 360 FT-IR instrument.

Powder XRD patterns were measured on a D/max-2400 (Rigaku, Japan) instrument using $\mathrm{Cu} \mathrm{K}_{\alpha}$ radiation.

Fe Mössbauer spectra were collected using a conventional constant acceleration spectrometer (Wissel, German) with a $25 \mathrm{~m} \mathrm{Ci}$ source of ${ }^{57} \mathrm{Co}$ in palladium at room temperature. The percentage of $\mathrm{Fe}, \mathrm{Fe}(\mathrm{II})$, and $\mathrm{Fe}(\mathrm{III})$ were calculated and contributor of magnetic behavior was confirmed.

Nitrogen adsorption-desorption experiments were carried out at $76.53 \mathrm{~K}$ on an ASAP 2010 accelerated surface area and porosimetry system (Micromeritics, USA). The Brunauer-Emmett-Teller (BET) surface area $\left(S_{\mathrm{BET}}\right)$ was calculated from the linearity of the BET equation. The surface

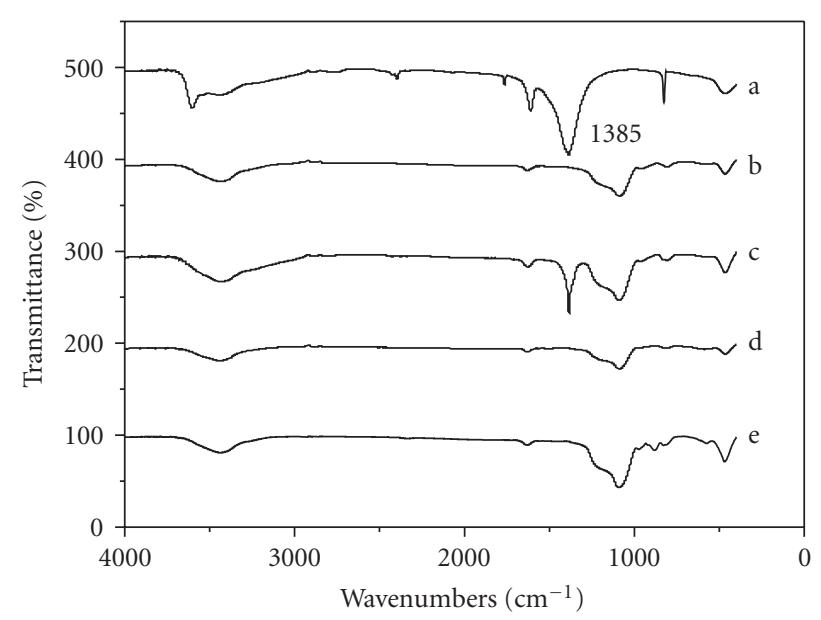

Figure 2: FT-IR spectra of (a) $\mathrm{Fe}\left(\mathrm{NO}_{3}\right)_{3}$, (b) SBA-15, (c) $\mathrm{Fe}\left(\mathrm{NO}_{3}\right)_{3}$ SBA-15, (d) $\mathrm{Fe}_{2} \mathrm{O}_{3}$-SBA-15, and (e) Fe-SBA-15.

area, volume and pore diameter were calculated from pore size distribution curves using the Barrett-Joyner-Halenda (BJH) formula.

The surface morphology of powders was observed under a JSM-6380LV scanning electron microscope (Jeol, Japan).

For TEM observation, samples were dispersed in ethanol, deposited on a grid of holey copper and transferred to a JEM-1230 emission electron microscope (Jeol, Japan) at an accelerating voltage of $100 \mathrm{kV}$.

A Lakeshore (USA) 7304 vibrating sample magnetometer was used to record magnetization curves of the samples.

2.4. Determination of Iron in Fe-SBA-15. A sample of $10 \mathrm{mg}$ of Fe-SBA-15 was heated in a mixture of hydrochloric acid and nitric acid to completely dissolve the iron and transferred to a $25-\mathrm{mL}$ volumetric flask and made up to volume with water. The solution was centrifuged at $10000 \mathrm{rpm}$ and the iron concentration was determined on an AA6800 instrument (Shimadzu, Japan). Standard $\mathrm{Fe}^{3+}$ solutions $\left(0,2.0,4.0,8.0,10.0 \mu \mathrm{g} \mathrm{mL}^{-1}\right)$ were measured to generate a standard curve.

2.5. Adsorption of Aromatic Compounds. Benzene, toluene, and ethyl benzene, were dissolved in deionized water at a concentration of $1.0 \mathrm{ppm}$ each. Then $20 \mathrm{mg}$ of Fe-SBA-15 was added to the aqueous solution and sonicated at room temperature (approx. $20^{\circ} \mathrm{C}$ ) for $30 \mathrm{~s}$ to form a homogeneous dispersion. After standing for 5 min, Fe-SBA- 15 was collected from the dispersion using a magnet and the supernatant was discarded. The absorbed model compounds were eluted in $0.5 \mathrm{~mL}$ of methanol. Finally, $1.0 \mu \mathrm{L}$ of the eluate was analyzed on a Varian (USA) CP-3380 gas chromatograph and the content of the aromatic compounds was calculated.

\section{Results and Discussion}

3.1. FT-IR. Figure 2 shows FT-IR spectra of $\mathrm{Fe}\left(\mathrm{NO}_{3}\right)_{3}$, SBA-15, $\mathrm{Fe}\left(\mathrm{NO}_{3}\right)_{3}-\mathrm{SBA}-15, \mathrm{Fe}_{2} \mathrm{O}_{3}$-SBA-15, and Fe-SBA-15. 


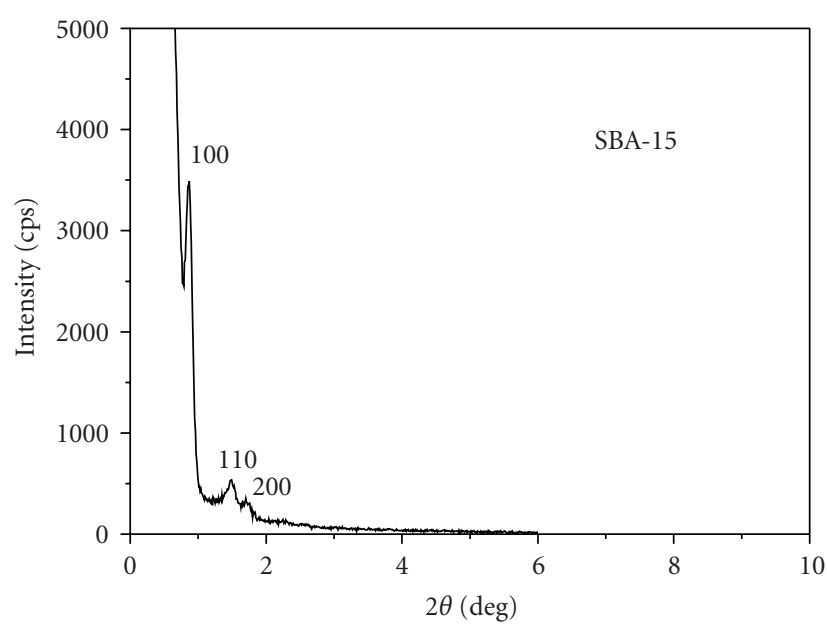

(a)

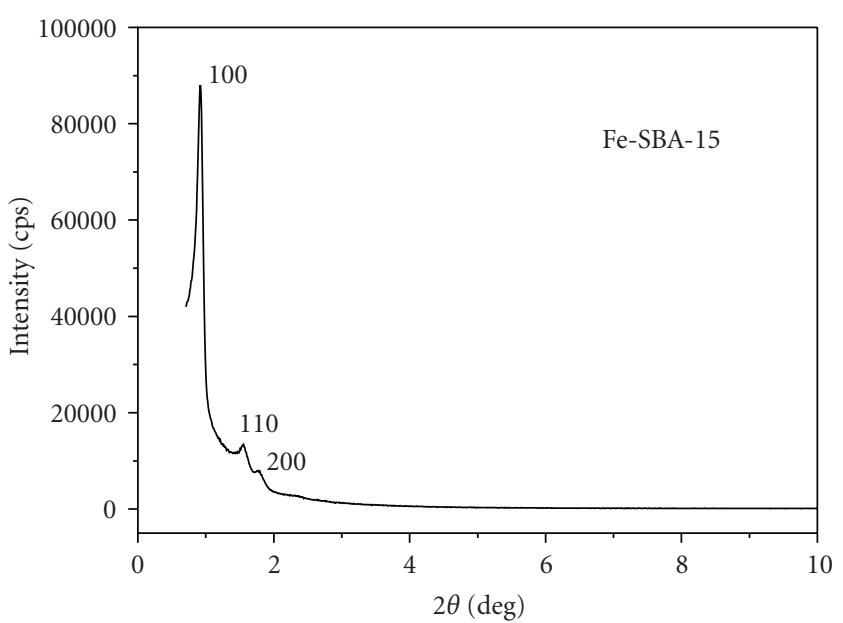

(b)

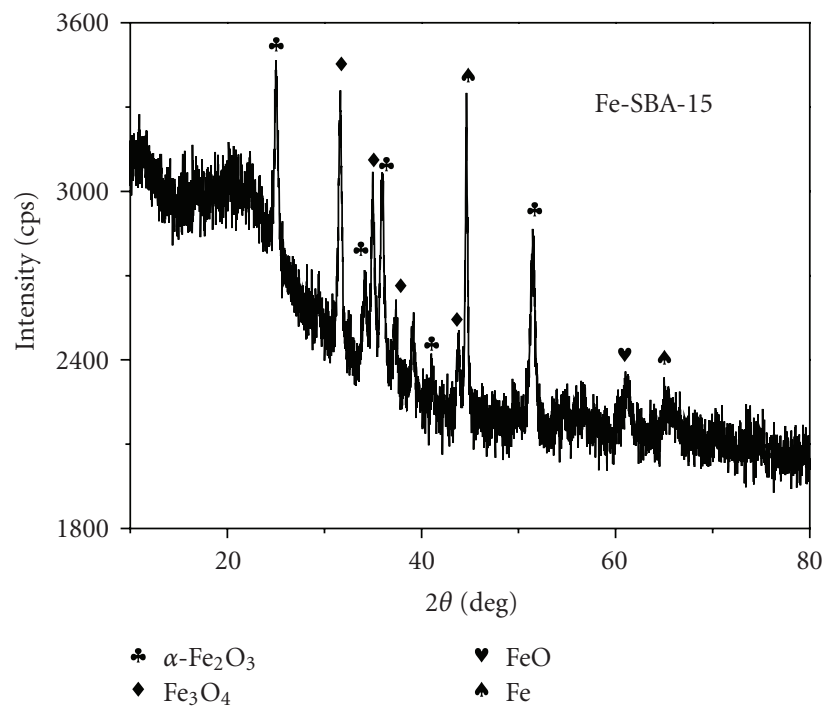

(c)

FIgure 3: Powder XRD spectra for SBA-15 and Fe-SBA-15.

The IR vibration for the $\mathrm{NO}_{3}{ }^{-}$ion at $1385 \mathrm{~cm}^{-1}$ is evident in curves a and c, but not in $b$, indicating that $\mathrm{Fe}\left(\mathrm{NO}_{3}\right)_{3}$-SBA15 was prepared successfully. $\mathrm{Fe}_{2} \mathrm{O}_{3}$-SBA- 15 was obtained by transformation from the nitrate to the oxide form, as confirmed by the disappearance of the peak at $1385 \mathrm{~cm}^{-1}$ after calcination (curve d) [16]. The peak at $1385 \mathrm{~cm}^{-1}$ also disappeared after $\mathrm{Fe}_{2} \mathrm{O}_{3}-\mathrm{SBA}-15$ reduction (curve e). The material was red after $\mathrm{Fe}\left(\mathrm{NO}_{3}\right)_{3}$-SBA-15 calcination at $750^{\circ} \mathrm{C}$, suggesting that iron oxide is mainly in the form of $\alpha-\mathrm{Fe}_{2} \mathrm{O}_{3}$ (hematite). Hematite is extremely stable under ambient conditions and is often the end product of the transformation of other iron oxides [17].

3.2. XRD and MS. XRD patterns of the materials are shown in Figure 3. In the narrow-angle range peaks for SBA-15 are evident at $0.8^{\circ}, 1.4^{\circ}$ and $1.7^{\circ}$. For Fe-SBA-15, there is one prominent peak at $0.9^{\circ}$ and two peaks at $1.5^{\circ}$ and $1.8^{\circ}$. These results indicate that magnetic Fe-SBA-15 still has a high degree of hexagonal symmetry $[1,19]$ and retains the structure of SBA- 15 after calcination at $750^{\circ} \mathrm{C}$ and reduction at $800^{\circ} \mathrm{C}$, indicating that SBA- 15 has good hydrothermal stability. Peaks for iron are evident at $44.6^{\circ}$ and $65^{\circ}$ in the wide-angle XRD pattern for Fe-SBA-15 [20, 21]. Other peaks can be attributed to $\mathrm{Fe}_{2} \mathrm{O}_{3}, \mathrm{Fe}_{3} \mathrm{O}_{4}$ or $\mathrm{FeO}$ [20-24]. Residual iron oxides may be a result of surface passivation [20], which can be explained by the following equations for reduction of $\mathrm{Fe}_{2} \mathrm{O}_{3}$ with hydrogen [25]:

$$
\begin{gathered}
3 \mathrm{Fe}_{2} \mathrm{O}_{3}+\mathrm{H}_{2} \longrightarrow 2 \mathrm{Fe}_{3} \mathrm{O}_{4}+\mathrm{H}_{2} \mathrm{O} \\
\mathrm{Fe}_{3} \mathrm{O}_{4}+4 \mathrm{H}_{2} \longrightarrow 3 \mathrm{Fe}+4 \mathrm{H}_{2} \mathrm{O} \\
(1-x) \mathrm{Fe}_{3} \mathrm{O}_{4}+(1-4 x) \mathrm{H}_{2} \longrightarrow 3 \mathrm{Fe}_{(1-x)} \mathrm{O}+(1-4 x) \mathrm{H}_{2} \mathrm{O}, \\
\mathrm{Fe}_{(1-x)} \mathrm{O}+\mathrm{H}_{2} \longrightarrow(1-x) \mathrm{Fe}+\mathrm{H}_{2} \mathrm{O}
\end{gathered}
$$


TABLE 1: Mössbauer parameters of Fe-SBA-15.

\begin{tabular}{|c|c|c|c|c|c|c|}
\hline Sample & Components & $\mathrm{IS}(\mathrm{mm} / \mathrm{s})$ & $\mathrm{QS}(\mathrm{mm} / \mathrm{s})$ & $H_{\text {eff }}(\mathrm{T})$ & FWHM $(\mathrm{mm} / \mathrm{s})$ & $G(\%)$ \\
\hline \multirow{3}{*}{ Fe-SBA-15 } & $\mathrm{Fe}$ & 0.38 & 0.93 & - & 0.44 & 17.0 \\
\hline & $\mathrm{Fe}^{2+}$ & 1.14 & 2.81 & - & 0.33 & 64.5 \\
\hline & $\mathrm{Fe}^{3+}$ & -0.002 & 0.01 & 33.03 & 0.24 & 18.5 \\
\hline
\end{tabular}

IS: isomer shift; QS: quadrupole splitting; $\mathrm{H}_{\text {eff }}$ : effective internal magnetic field; FWHM: full line width at half maximum; $G$ : relative weight of the partial components in the spectra.

TABLE 2: Pore parameters for SBA-15 and Fe-SBA-15.

\begin{tabular}{lccccc}
\hline Sample & $d_{(100)}{ }^{\mathrm{a}}(\AA)$ & $S_{\mathrm{BET}}\left(\mathrm{m}^{2} \mathrm{~g}^{-1}\right)$ & $S_{\mathrm{BJH}}\left(\mathrm{m}^{2} \mathrm{~g}^{-1}\right)$ & $V_{\mathrm{BJH}}\left(\mathrm{cm}^{3} \mathrm{~g}^{-1}\right)$ & 0.99 \\
\hline SBA-15 & 95.6 & 524 & 546 & 0.56 & 72.8 \\
Fe-SBA-15 & 83.0 & 308 & 352 & 0.56 \\
\hline
\end{tabular}

${ }^{\mathrm{a}}$ Large unit cell parameter $a_{0}=2 d_{(100)} / \sqrt{ } 3[18]$.

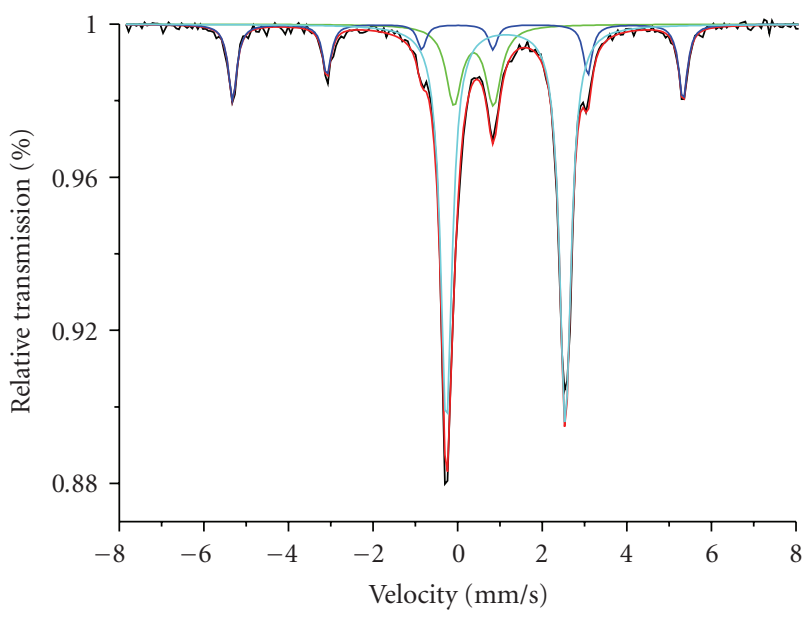

Figure 4: Mössbauer spectra of Fe-SBA-15.

Figure 4 shows Mössbauer spectra of Fe-SBA-15 and Table 1 shows Mössbauer parameters of Fe-SBA-15. From the calculation of Fe Mössbauer spectra, the percentage of $\mathrm{Fe}, \mathrm{Fe}(\mathrm{II})$, and $\mathrm{Fe}(\mathrm{III})$ in the prepared materials were $17.0 \%$, $64.5 \%$, and $18.5 \%$, respectively. The above results could also confirm that the reduction process followed the equations and the reduction was not complete under this condition. Furthermore, it can be seen that the magnetic behavior of Fe-SBA- 15 was contributed by $\mathrm{Fe}_{3} \mathrm{O}_{4}$.

3.3. Nitrogen Adsorption-Desorption Measurements. Figure 5 shows nitrogen adsorption-desorption isotherms for the materials, which exhibit a typical type IV isotherm with an $\mathrm{H} 1$ hysteresis loop as defined by IUPAC [26]. The $\mathrm{H} 1$ hysteresis loop indicates that Fe-SBA-15 was still a mesoporous material. However, there was a shift in hysteresis position to lower relative pressure and a decreasing trend. The shift of the sharp inflection from $P / P_{0} 0.60$ to 0.80 is characteristic of a diameter in the mesopore range [27, 28]. Pore parameters for the materials are shown in Table 2. The BET surface area changed from 524 to $308 \mathrm{~m}^{2} \mathrm{~g}^{-1}$ and the pore diameter decreased from 72.8 to $72.6 \AA$ on modification

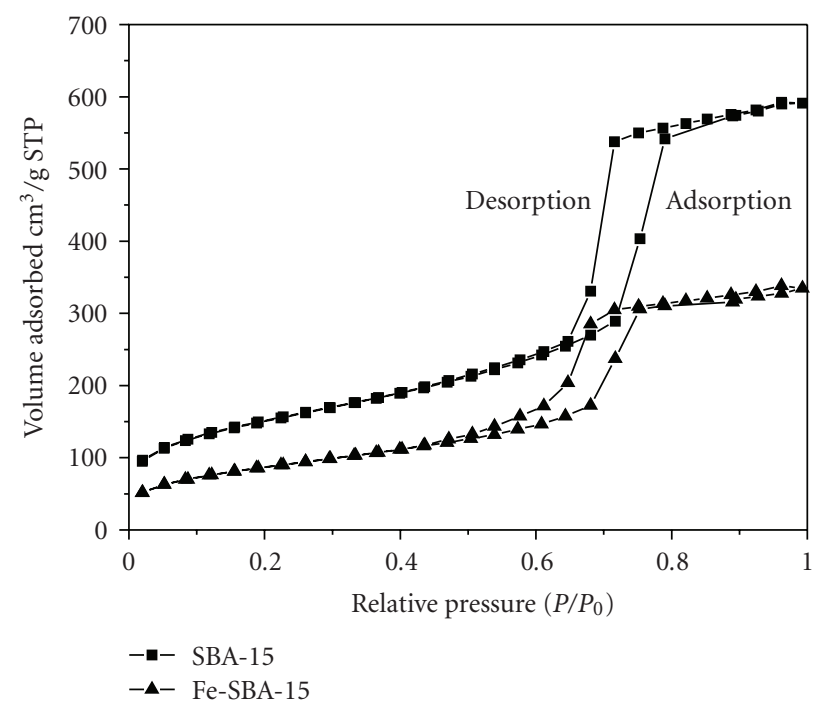

FIGURE 5: Nitrogen adsorption/desorption isotherms for SBA-15 and Fe-SBA-15.

of SBA-15 with Fe. The decrease in surface area and pore diameter, probably caused by filling of the pores with small iron particles, indicates successful iron doping within the mesoporous channels of SBA-15 [29]. The pore diameter and $d_{100}$ data for the two materials indicate that the mesopore uniformity of the parent SBA-15 silica was retained in the modified material [27].

3.4. SEM. SEM images of SBA-15 before and after modification are shown in Figure 6. Large fibrous structures of $30-80 \mu \mathrm{m}$ in length and $10-20 \mu \mathrm{m}$ in diameter are clearly evident in Figure 6. Compared to the parent SBA-15, the size of the modified material decreased on both a microscopic and macroscopic scale, suggesting that the particle size can change on ultrasonication.

3.5. TEM. The TEM images in Figure 7 provide direct evidence that the material comprises well-ordered hexagonal arrays of mesopores (1D channel) and a 2D hexagonal 


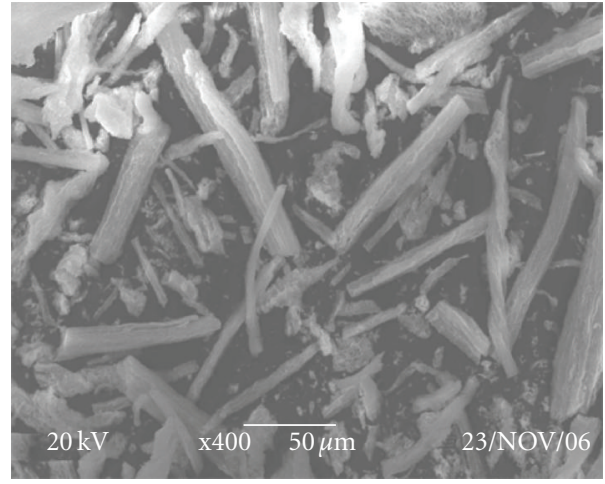

(a)

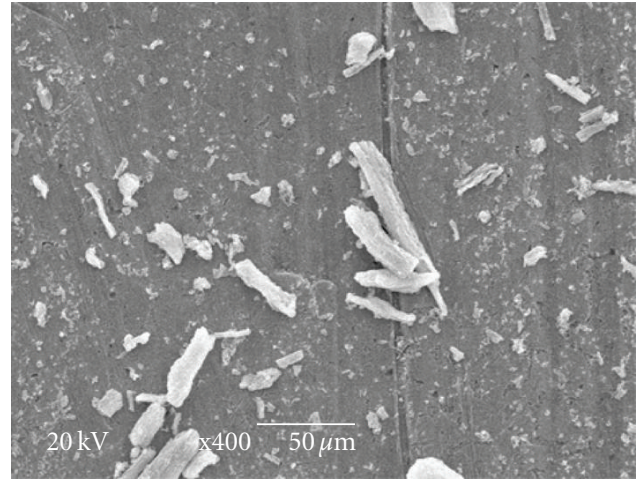

(b)

Figure 6: SEM images of (a) SBA-15 and (b) Fe-SBA-15.

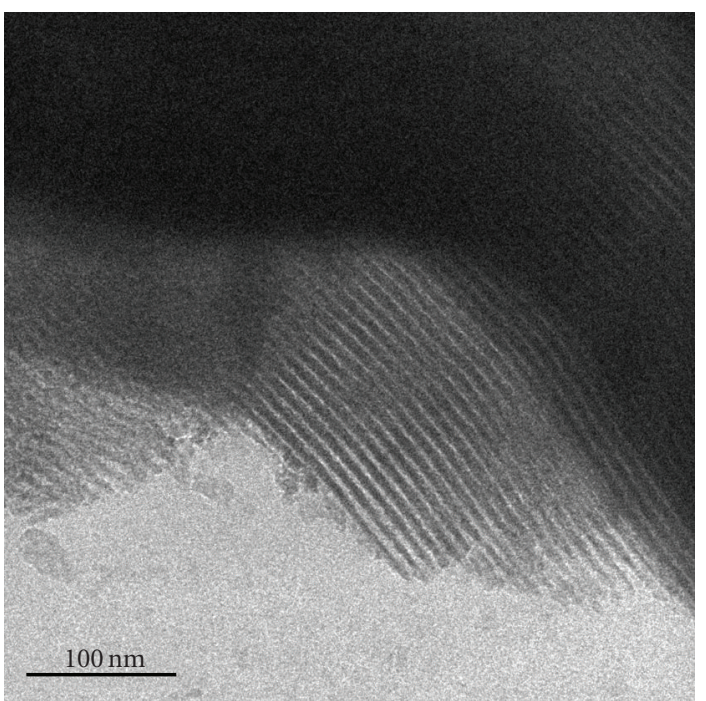

(a)

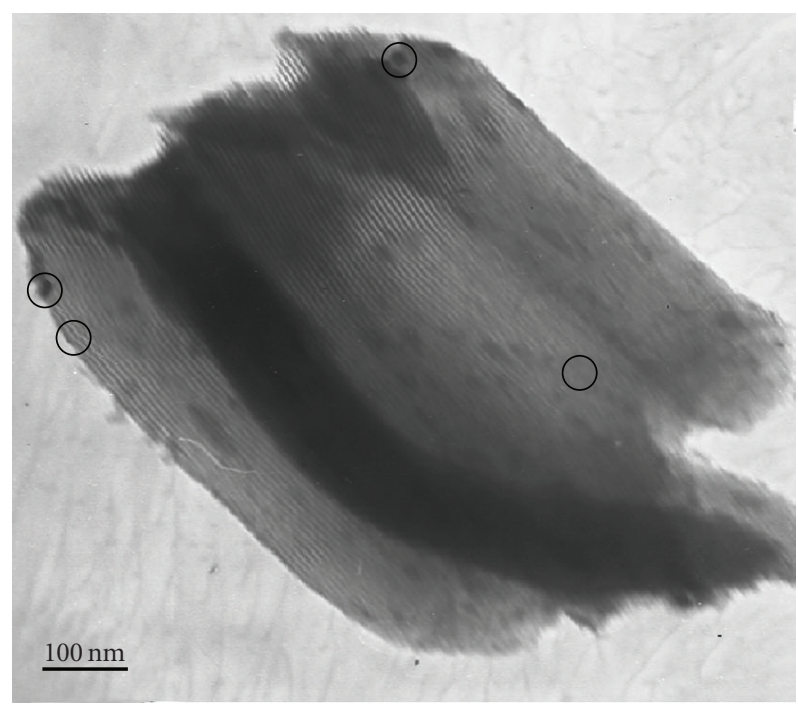

(b)

FIgURE 7: TEM images of (a) SBA-15 and (b) Fe-SBA-15 (circles indicate large iron metal particles).

structure [30]. The TEM image of Fe-SBA-15 (Figure 6(b)) shows that the structure is the same as in the parent SBA-15 silica. IR and nitrogen adsorption-desorption measurements confirmed that iron was doped in SBA-15. TEM and XRD results also confirmed that modification occurred within pores and that the SBA-15 structure did not change. The modified material retained the mesopore uniformity of the original inorganic wall structure of the parent SBA-15 silica [27].

3.6. Magnetic Behavior of Fe-SBA-15. Figure 8 shows that Fe-SBA-15 exhibited strong magnetic behavior with a magnetization value of $8.8 \mathrm{emu} \mathrm{g}^{-1}$, confirming that Fe-SBA-15 was magnetic with potential as a magnetic adsorbent for removal of aromatic compounds from water.

Using AAS data, the iron content of Fe-SBA-15 was calculated as $A=0.0794 C+0.0249(R=0.9993)$, where $A$

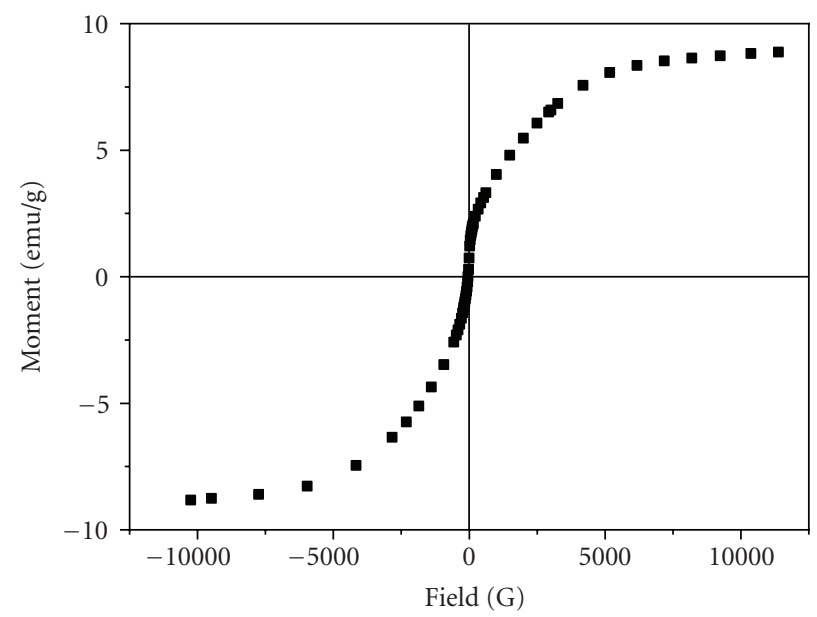

FIgURE 8: Magnetization curve for Fe-SBA-15. 


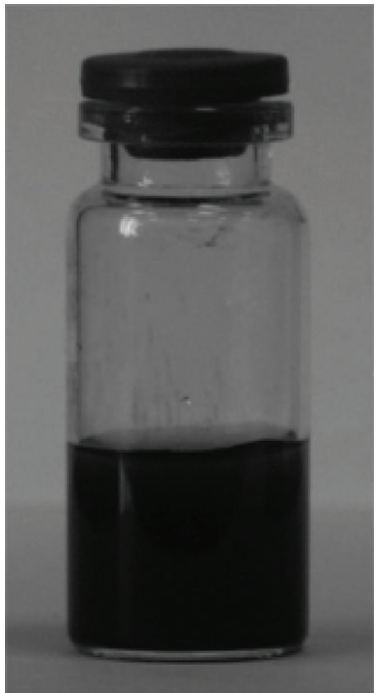

Dispersion

(a)

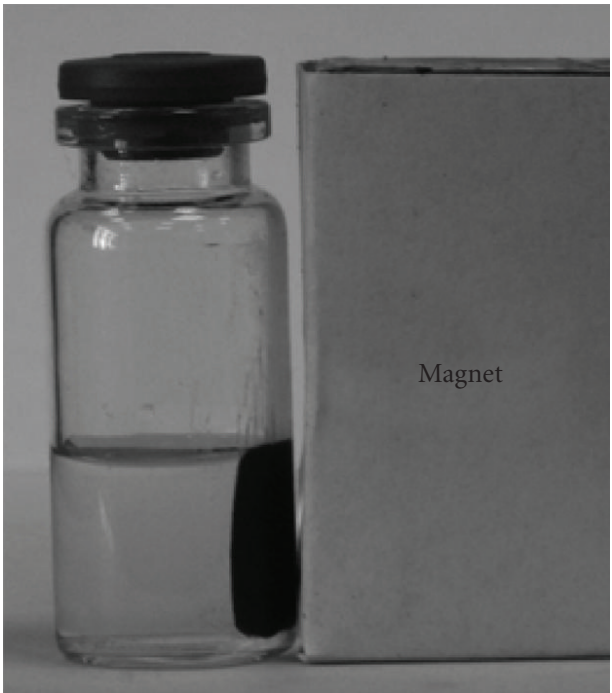

Magnetic separation

(b)

FIGURE 9: Photographs of (a) dispersion and (b) magnetic separation of magnetic Fe-SBA-15.

is the sample absorbance and $C$ is the sample concentration. The iron load was thus determined to be $19.1 \mathrm{wt} . \%$ in the modified material, in accordance with its strong magnetic behavior.

There are two possible explanations for the strong magnetic behavior of Fe-SBA-15. First, Fe-SBA-15 was prepared with a high content iron. Second, iron may aggregate in SBA15 channels during calcination and reduction. Large iron metallic particles that formed in Fe-SBA-15 can be observed in Figure 6(b).

3.7. Adsorption of Aromatic Compounds. Figure 9 shows the magnetic separation process for magnetic Fe-SBA-15. Fe-SBA-15 was fully dispersed by reciprocating oscillation. After $5 \mathrm{~min}$, a magnet was fixed to the vessel wall to attract the material. Following the absorption process, Fe-SBA15 was redispersed in methanol to desorb the aromatic compounds and the efficiency of magnetic separation was assessed by GC.

Analytical data for benzene, toluene, and ethyl benzene compared to standards revealed removal of $90.6 \%, 88.7 \%$, and $85.4 \%$, respectively, demonstrating that Fe-SBA-15 can be used as a sorbent in water. It is worth noting that Fe-SBA15 can be reused after washing several times with methanol and vacuum drying.

\section{Conclusions}

Magnetic Fe-SBA-15 was prepared from mesoporous silica molecular sieves via a simple iron ion doping of SBA-15, transformation to $\mathrm{Fe}_{2} \mathrm{O}_{3}$ and then reduction to magnetic iron particles using $\mathrm{H}_{2}$. Results confirm that the modified material retained the well-ordered hexagonal mesoporous structure after calcination at $800^{\circ} \mathrm{C}$. Mesoporous silica materials may have further application potential, such as in sensing materials, solid supports, and nanobioelectronics, especially as magnetic sorbents allow the reuse of adsorbent materials for several cycles.

\section{Acknowledgments}

This work was supported by the National Natural Science Foundation of China (no. 20775029), the Program for New Century Excellent Talents in University (NCET-07-0400), and the Central Teacher Plan of Lanzhou University.

\section{References}

[1] D. Zhao, J. Feng, Q. Huo et al., "Triblock copolymer syntheses of mesoporous silica with periodic 50 to 300 angstrom pores," Science, vol. 279, no. 5350, pp. 548-552, 1998.

[2] J. Zhao, F. Gao, Y. Fu, W. Jin, P. Yang, and D. Zhao, "Biomolecule separation using large pore mesoporous SBA15 as a substrate in high performance liquid chromatography," Chemical Communications, no. 7, pp. 752-753, 2002.

[3] A. M. Liu, K. Hidajat, S. Kawi, and D. Y. Zhao, "A new class of hybrid mesaporous materials with functionalized organic monolayers for selective adsorption of heavy metal ions," Chemical Communications, no. 13, pp. 1145-1146, 2000.

[4] H. Huang, C. Yang, H. Zhang, and M. Liu, "Preparation and characterization of octyl and octadecyl-modified mesoporous SBA-15 silica molecular sieves for adsorption of dimethyl phthalate and diethyl phthalate," Microporous and Mesoporous Materials, vol. 111, no. 1-3, pp. 254-259, 2008.

[5] R. Tian, J. Sun, H. Zhang et al., "Large-pore mesoporous SBA15 silica particles with submicrometer size as stationary phases for high-speed CEC separation," Electrophoresis, vol. 27, no. 4, pp. 742-748, 2006.

[6] Y. Zhang, R. Liu, Y. Hu, and G. Li, "Microwave heating 
in preparation of magnetic molecularly imprinted polymer beads for trace triazines analysis in complicated samples," Analytical Chemistry, vol. 81, no. 3, pp. 967-976, 2009.

[7] J. Jin, R. Li, H. Wang, H. Chen, K. Liang, and J. Ma, "Magnetic Fe nanoparticle functionalized water-soluble multi-walled carbon nanotubules towards the preparation of sorbent for aromatic compounds removal," Chemical Communications, no. 4, pp. 386-388, 2007.

[8] Y. Deng, W. Yang, C. Wang, and S. Fu, "A novel approach for preparation of thermoresponsive polymer magnetic microspheres with core-shell structure," Advanced Materials, vol. 15, no. 20, pp. 1729-1732, 2003.

[9] Y. Deng, C. Deng, D. Yang, C. Wang, S. Fu, and X. Zhang, "Preparation, characterization and application of magnetic silica nanoparticle functionalized multi-walled carbon nanotubes," Chemical Communications, no. 44, pp. 5548-5550, 2005.

[10] AN. H. Lu, W. Schmidt, N. Matoussevitch et al., "Nanoengineering of a magnetically separable hydrogenation catalyst," Angewandte Chemie. International Edition, vol. 43, no. 33, pp. 4303-4306, 2004.

[11] AN. H. Lu, W. C. Li, A. Kiefer et al., "Fabrication of magnetically separable mesostructured silica with an open pore system," Journal of the American Chemical Society, vol. 126, no. 28, pp. 8616-8617, 2004.

[12] Y. Du, S. Liu, Y. Ji, Y. Zhang, NI. Xiao, and F. S. Xiao, “Ordered mesoporous silica materials (SBA-15) with good heat-resistant magnetism," Journal of Magnetism and Magnetic Materials, vol. 320, no. 13, pp. 1932-1936, 2008.

[13] H. X. Jin, L. Li, N. J. Chu et al., "Magnetic properties of nanocomposite Fe-doped SBA-15 magnetic materials," Materials Chemistry and Physics, vol. 112, no. 1, pp. 112-114, 2008.

[14] J. S. Jung, K. H. Choi, Y. K. Jung et al., "Preparation and characterization of $\gamma$-FeO nanoparticles in SBA15 host material," Journal of Magnetism and Magnetic Materials, vol. 272-276, no. 1, pp. e1157-e1159, 2004.

[15] H. H. P. Yiu, M. A. Keane, Z. A. D. Lethbridge, M. R. Lees, A. J. El Haj, and J. Dobson, "Synthesis of novel magnetic iron metal-silica (Fe-SBA-15) and magnetite-silica (FeO-SBA-15) nanocomposites with a high iron content using temperatureprogramed reduction," Nanotechnology, vol. 19, no. 25, Article ID 255606, 2008.

[16] H. Huwe and M. Fröba, "Synthesis and characterization of transition metal and metal oxide nanoparticles inside mesoporous carbon CMK-3," Carbon, vol. 45, no. 2, pp. $304-$ 314, 2007.

[17] A. S. Teja and P.-Y. Koh, "Synthesis, properties, and applications of magnetic iron oxide nanoparticles," Progress in Crystal Growth and Characterization of Materials, vol. 55, no. 1-2, pp. 22-45, 2009.

[18] L. Vradman, L. Titelman, and M. Herskowitz, "Size effect on SBA-15 microporosity," Microporous and Mesoporous Materials, vol. 93, no. 1-3, pp. 313-317, 2006.

[19] A. Sayari, B. H. Han, and Y. Yang, "Simple synthesis route to monodispersed SBA-15 silica rods," Journal of the American Chemical Society, vol. 126, no. 44, pp. 14348-14349, 2004.

[20] B. Lv, Y. Xu, D. Wu, and Y. Sun, "Preparation and magnetic properties of spindle porous iron nanoparticles," Materials Research Bulletin, vol. 44, no. 5, pp. 961-965, 2009.

[21] A. Gervasini, C. Messi, P. Carniti, A. Ponti, N. Ravasio, and F. Zaccheria, "Insight into the properties of Fe oxide present in high concentrations on mesoporous silica," Journal of Catalysis, vol. 262, no. 2, pp. 224-234, 2009.

[22] K. -S. Chou and S. -J. Lee, "Facile methods to synthesize nanaosized iron oxide colloidal dispersion and its characterization," Colloids and Surfaces A, vol. 336, no. 1-3, pp. 23-28, 2009.

[23] Y. Wang, C. S. Liu, F. B. Li, C. P. Liu, and J. B. Liang, "Photodegradation of polycyclic aromatic hydrocarbon pyrene by iron oxide in solid phase," Journal of Hazardous Materials, vol. 162, no. 2-3, pp. 716-723, 2009.

[24] B. Lv, Y. Xu, D. Wu, and Y. Sun, "Preparation and properties of magnetic iron oxide nanotubes," Particuology, vol. 6, no. 5, pp. 334-339, 2008.

[25] A. Pineau, N. Kanari, and I. Gaballah, "Kinetics of reduction of iron oxides by $\mathrm{H}$. Part I: low temperature reduction of hematite," Thermochimica Acta, vol. 447, no. 1, pp. 89-100, 2006.

[26] K. S. W. Sing, D. H. Everett, R. A. W. Haul et al., "Reporting physisorption data for gas/solid systems with special reference to the determination of surface area and porosity," Pure and Applied Chemistry, vol. 57, no. 4, pp. 603-619, 1985.

[27] Z. Luan, J. A. Fournier, J. B. Wooten, and D. E. Miser, "Preparation and characterization of (3-aminopropyl) triethoxysilane-modified mesoporous SBA-15 silica molecular sieves," Microporous and Mesoporous Materials, vol. 83, no. 1-3, pp. 150-158, 2005.

[28] A. L. Doadrio, E. M. B. Sousa, J. C. Doadrio, J. Pérez Pariente, I. Izquierdo-Barba, and M. Vallet-Regí, "Mesoporous SBA15 HPLC evaluation for controlled gentamicin drug delivery," Journal of Controlled Release, vol. 97, no. 1, pp. 125-132, 2004.

[29] S. A. Mirji, S. B. Halligudi, D. P. Sawant et al., "Adsorption of octadecyltrichlorosilane on mesoporous SBA-15," Applied Surface Science, vol. 252, no. 12, pp. 4097-4103, 2006.

[30] H. Hoffmann, U. Mayer, and A. Krischanitz, "Structure of alkylsiloxane monolayers on silicon surfaces investigated by external reflection infrared spectroscopy," Langmuir, vol. 11, no. 4, pp. 1304-1312, 1995. 


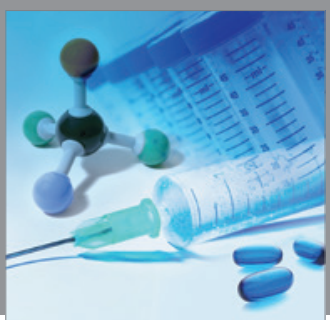

International Journal of

Medicinal Chemistry

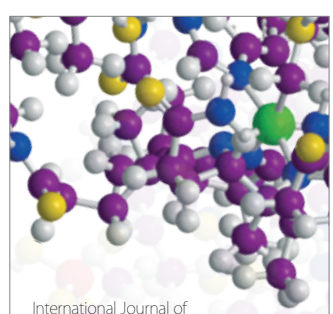

Carbohydrate Chemistry

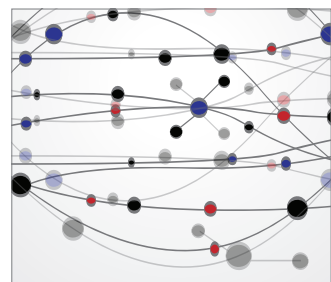

The Scientific World Journal
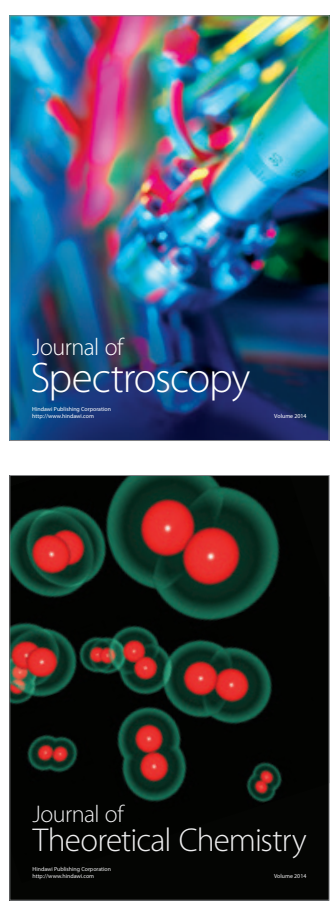
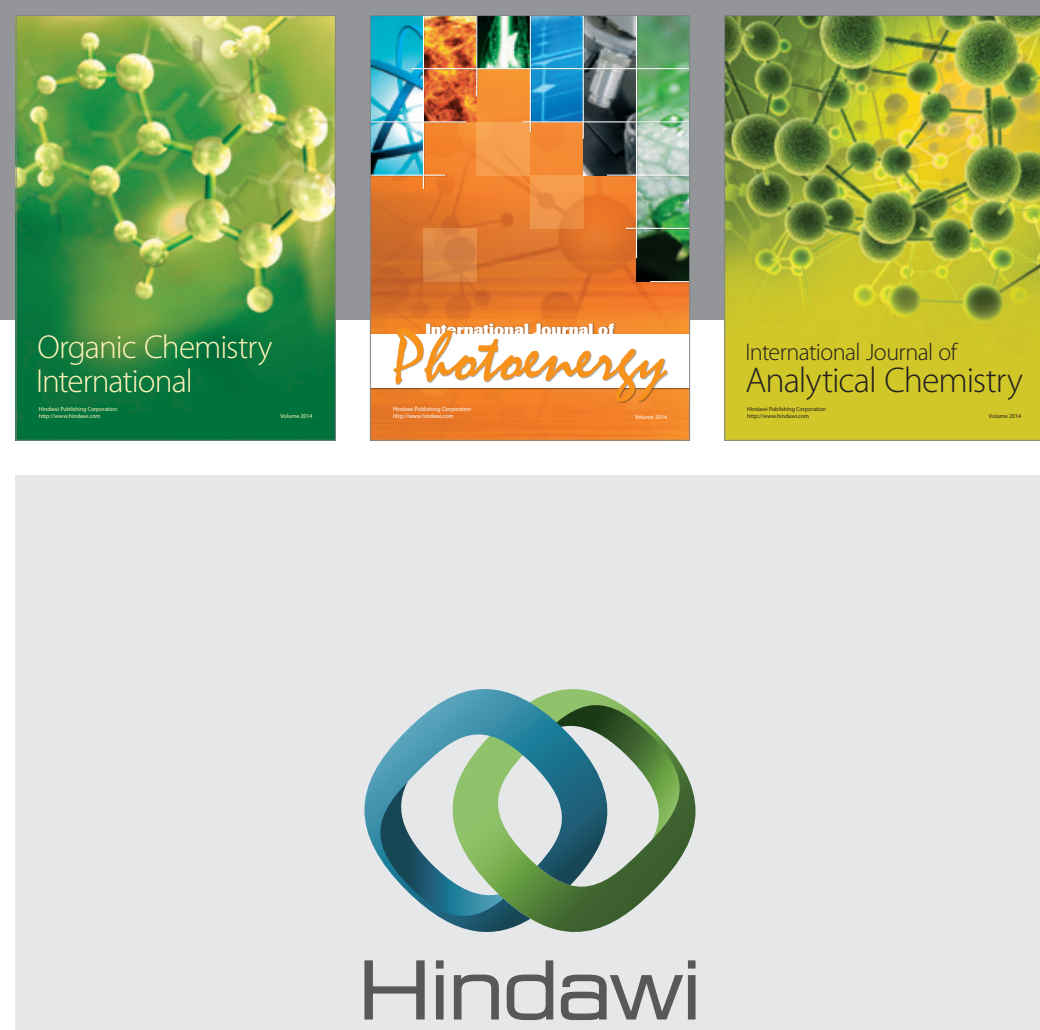

Submit your manuscripts at

http://www.hindawi.com
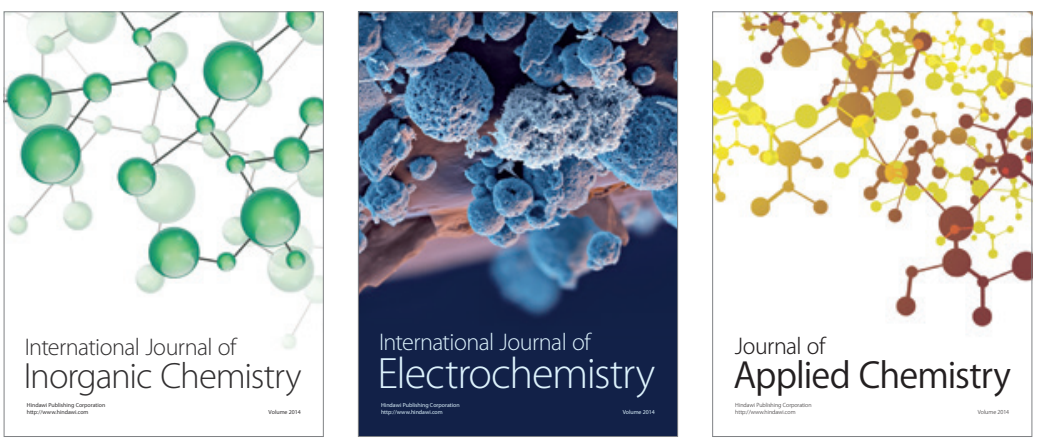

Journal of

Applied Chemistry
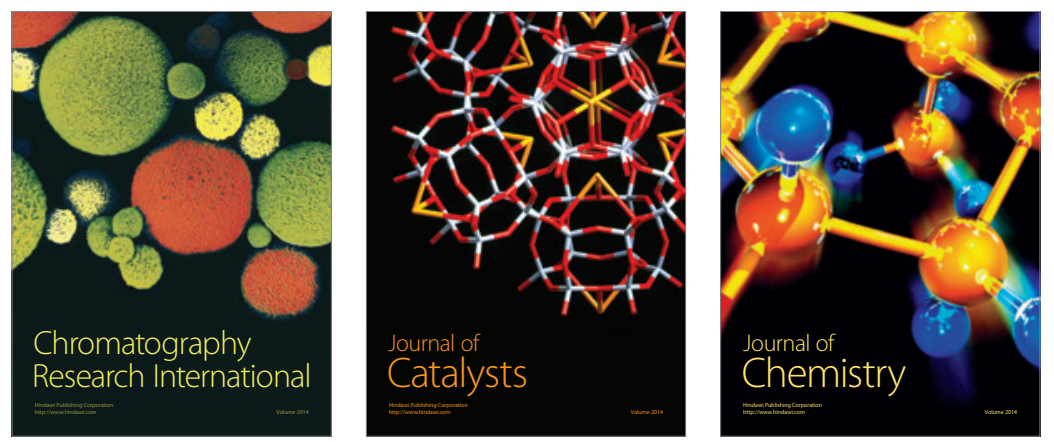
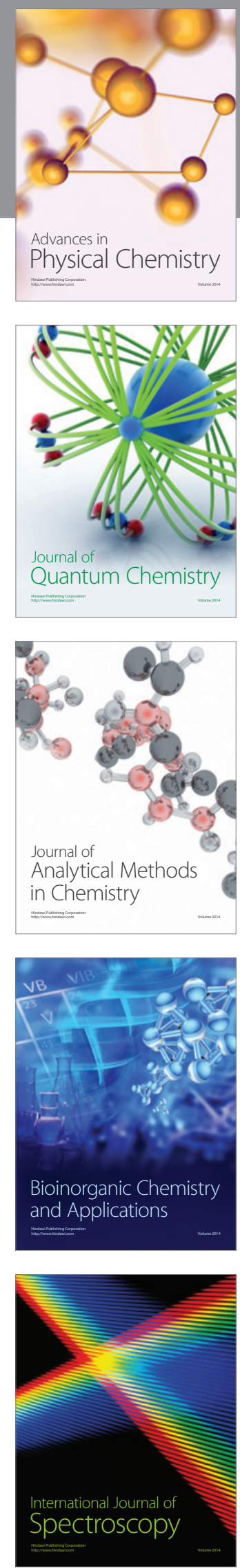